\title{
Diálogo necessário entre a geografia e a literatura infantil nas séries iniciais do ensino fundamental
}

\author{
Francielle Bonfim Beraldi ${ }^{1}$ \\ Prof. Dr. Cláudio Benito de Oliveira Ferraz ${ }^{2}$
}

${ }^{1}$ Professora de Educação Básica no município de Presidente Prudente - SP e mestranda do Programa de Pós Graduação em Geografia da Universidade Federal da Grande Dourados - MS (UFGD).

${ }^{2}$ Professor na Universidade Estadual Paulista (UNESP), campus de Presidente Prudente - SP, e do Programa de PósGraduação em Geografia da Universidade Federal da Grande Dourados - UFGD. Coordenador do Grupo de Pesquisas Linguagens Geográficas.

Recebido em 04/2012. Aceito para publicação em 12/2012.

Versão online publicada em 01/02/2013 (http://seer.ufrgs.br/paraonde)

\begin{abstract}
Resumo: 0 presente texto trata da relação entre a Geografia e a Literatura nas séries iniciais do Ensino Fundamental. Trabalhar com as séries iniciais é um desafio, na medida em que comumente professores graduados em Geografia trabalham nas séries finais do ensino fundamental e no Ensino Médio. No entanto, é matéria que interessa à Geografia como um todo porque, nas salas das séries iniciais, a ciência geográfica está sendo colocada em movimento, e acreditamos que tem um papel fundamental na formação do aluno, tanto em sua vida escolar, como em seu relacionamento no mundo que o rodeia. Como estamos falando de séries iniciais e de um alunado de 5 a 9 anos, aproximadamente, vamos nos debruçar por sobre a relação entre a Geografia e a Literatura Infantil. O lugar da pesquisa, Dourados, município que fica a sudoeste do estado do Mato Grosso do Sul, está situado na faixa de fronteira (BrasilParaguai), torna ainda mais interessante o trabalho de relacionar a Geografia com a Literatura Infantil. Isto porque sua localização é relativamente distante de grandes centros editoriais, e é visível que nos livros didáticos não há muita relação com a realidade do lugar, a questão da fronteira e suas especificidades. A Literatura infantil pode ser um atalho para o professor, uma forma de estar próximo ao ensino da Língua Materna, enquanto componente curricular mais cobrado nas avaliações institucionais do Sistema de Avaliação da Educação Básica, e ao mesmo tempo lecionar de forma interessante e valorativa a Geografia, que traz esclarecimentos à questões acerca do espaço vivido. Durante a pesquisa em curso, muitos textos interessantes foram encontrados nos livros didáticos de Geografia apontados pelos professores de sete escolas do município de Dourados- MS. Da análise destes textos é possível inferir que, através da Literatura Infantil é possível falar de Geografia numa perspectiva que reconheça o conhecimento a priori do aluno, ao mesmo tempo, amplie o seu conhecimento de mundo e seja uma ciência dotada de sentido e importância no cotidiano do aluno das séries iniciais.
\end{abstract}

Palavras-chave: Geografia. Literatura Infantil. Séries Iniciais. Currículo.

\section{Introdução}

As séries iniciais a que nos referimos neste trabalho compreendem do $1^{\circ}$ ao $5^{\circ}$ ano do Ensino Fundamental, ciclo em que os componentes curriculares são ministrados por professores com formação mais generalizada em Pedagogia e não tendo, em sua maioria, a especialização em Geografia. Contudo, nesta etapa de ensino, a Geografia está presente e deve ser ministrada com base principalmente nos Parâmetros Curriculares Nacionais (1997), em consonância com os conteúdos das propostas curriculares de cada estado brasileiro.

As grades curriculares das séries iniciais contêm uma carga muito reduzida de Geografia pois, na maioria das vezes, a prioridade é com os conteúdos relacionados ao ensino da Língua Materna e da Matemática. Nossa abordagem aqui não visa defender uma espécie de corporativismo, no qual o conteúdo de Geografia nas séries iniciais deve ser trabalhado por formados nessa área do conhecimento, pois entendemos que a potência inerente ao professor dessa fase de ensino é voltada para outra perspectiva, mais relacionada com as práticas de alfabetização e do domínio de linguagens científicas e artísticas fundamentais para o decorrer dos anos escolares e para a vida futura dos alunos. A questão que se coloca é outra, ou seja, defendemos que o trabalho com o conteúdo geográfico não deve ser entendido em separado dos demais conteúdos e atividades de alfabetização. Portanto, para que a Geografia tenha espaço nas 
séries iniciais, é preciso que ela dialogue também com outros componentes do currículo, para ser significativa e possibilitar ao professor articular os diversos saberes dentro do seu planejamento.

Referimo-nos neste texto à relação entre a Geografia e Literatura por acreditarmos que esta associação é interessante, produtiva ao aproximar os conteúdos da Língua Materna com a Geografia, sem prejuízo para nenhuma das partes. No próprio texto dos Parâmetros Curriculares Nacionais de Geografia (1997) em sua parte 2 intitulada Aprender e Ensinar Geografia está previsto que:

Mesmo na escola, a relação da Geografia com a Literatura, por exemplo, tem sido redescoberta, proporcionando um trabalho que provoca interesse e curiosidade sobre a leitura do espaço e da paisagem. É possível aprender Geografia desde os primeiros ciclos do ensino fundamental através da leitura de autores brasileiros consagrados Jorge Amado, Érico Veríssimo, Graciliano Ramos, Guimarães Rosa, entre outros - cujas obras retratam diferentes paisagens do Brasil, em seus aspectos sociais, culturais e naturais. Também as produções musicais, a fotografia e até mesmo o cinema são fontes que podem ser utilizadas por professores e alunos para obter informações, comparar, perguntar e inspirar-se para interpretar as paisagens e construir conhecimentos sobre o espaço geográfico.

Neste contexto, passamos a perscrutar a importância e pertinência de agenciar as linguagens artística da literatura com a científica da Geografia, notadamente, no nosso caso, no interior de um ciclo escolar em que tanto os alunos quanto a maioria dos professores não são geógrafos de formação. Diante disso, perguntamos quais seriam as contribuições e o que tem sido produzido neste sentido no cenário nacional.

De forma geral, podemos observar que desde o nascedouro moderno desse ramo científico, o uso dos textos literários se faz presente. Alexander von Humboldt lembra em vários momentos de sua obra da importância da poesia e da literatura em geral para se fazer um geodiagnóstico ou para uma geoanálise. É o caso, a título de exemplo, do clássico Cosmos (1858): em inúmeras passagens, Humboldt faz uso dos grandes nomes da literatura para enfatizar suas abordagens sobre o vulcanismo, comportamento das massas de ar, descrição das espécies vegetais, do comportamento humano etc.

Publicações recentes e eventos estão sendo constantemente produzidos para discutir a relação entre a Literatura e a Geografia ${ }^{3}$, mas é necessário pensar mais detalhadamente nesses diálogos, notadamente em relação ao ensino da Geografia, pois não podemos mais restringir a riqueza desse encontro a um mero exemplificar com trechos literários a temas e questões geográficas já de antemão prontas, cabendo ao professor do ensino fundamental e médio apenas reproduzir os determinados conteúdos para os alunos então memorizar mesmos, sem ao menos pensar na possibilidade de criar outros sentidos espaciais a partir desse diálogo entre a arte literária e a ciência dos estudos espaciais.

\section{Geografia e Literatura nas séries iniciais do Ensino Fundamental: diálogo necessário}

O livro não é a imagem do mundo segun-
do uma crença enraizada. Ele faz rizoma
com o mundo, há evolução a-paralela do
livro e do mundo, o livro assegura a des-
territorialização do mundo, mas o
mundo opera uma deterritorialização do
livro, que se desterritorializa por sua vez
em si mesmo no mundo (se ele é disto
capaz ese ele pode).

Deleuze e Guattari (1995)

A relação entre a Geografia e a Literatura proposta neste texto envolve a ciência geográfica enquanto linguagem, enquanto ferramenta que nos conduz a refletir sobre o lugar, o espaço e o território, além de outras variáveis importantes para a compreensão do espaço vivido. Destas reflexões muitas geografias hão de ser produzidas, tendo em vista que esta não é ciência imutável, por falar de espaços que estão sempre mudando e ganhando novas nuances. No entanto, nem sempre a Geografia trabalhada em sala de aula consegue construir ligações com o espaço vivido.

Mas há espaço para a Literatura em uma

${ }^{3}$ Como exemplo recente tivemos no Brasil a publicação do Atlas das Representações Literárias de Regiões Brasileiras (2006), publicado pelo Instituto Brasileiro de Geografia e Estatística; a obra A Literatura no Caminho da Historia e da Geografia, de Ortega e Cortez (2009); as traduções dos capítulos do livro Des Romans-geographes, de Marc Brosseau, coordenadas por Roberto Lobato Corrêa e Zeny Rosendahl (2007); o clássico trabalho de Carlos Augusto de Figueiredo Monteiro O Mapa e a Trama (2002); os livros Geografia e Literatura: ensaios sobre geograficidade, poética e imaginação, organizado por Marandola Jr. e Gratão (2010) e Transfazer o Espaço: ensaios de como a literatura vira espaço e vice-versa, organizado por Goettert e Marschner (2011), que constituem alguns dos trabalhos que vem produzindo, através de diferentes metodologias e enfoques, relações entre a Geografia e a Literatura. 
ciência que tem como tradição a elaboração de um saber padronizador, classificador, ordenador do território, tomado como base física e geometrizável, de um espaço em que se exerce o poder por meio do aparato administrativo do Estado-Nação ou, como colocam Gilles Deleuze e Felix Guattari (1995), um saber baseado em um pensamento arborescente.

Tendo clareza de que a forma como a ciência analisa, investiga e interfere no espaço é mais uma visão dentre outras acerca do mundo, precisamos estar atentos para outras formas de ver que estão sendo produzidas por diferentes áreas do conhecimento como a Pintura, a Música, o Cinema, a Literatura. Estas apresentam olhares acerca de uma mesma realidade e levam a reflexões que podem ser extremamente produtivas no âmbito da ciênciageográfica.

Ruy Moreira (2007), ao falar da relação entre a Geografia e diferentes olhares e expressões acerca do mundo, parece demonstrar uma angústia que se constitui naquele nó cego por ele identificado na trajetória do geógrafo, dividido entre o saber científico e um saber capaz de dialogar com outras formas de representar o mundo.

[...] ver o mundo pelos olhos da Arte, tanto quanto a arte vê o mundo pelos olhos da Geografia. Fundir num só os olhares imagéticos sobre os espaços da geografia, ciências sociais, literatura, pintura, cinema, arquitetura, veres geográficos [...]. Acostumados com o objetivo que impregnou o mundo da ciência, dissociamos no mundo o que é dela e o que é da arte. Não nos indagamos se não é este o nó cego que, até agora, afastou o olhar do geógrafo da capacidade de ver e acompanhar o mundo como o espaço tenso do ser contraditório

A literatura traz para o geógrafo uma oportunidade de expandir os horizontes da Geografia, fornece matéria-prima para pensar o espaço, pelo olhar de escritores que simulam diversas realidades. 0 mundo não aparece de forma fragmentada e dividida aos nossos olhos. Ele traz os eventos do cotidiano como bombas de nuances, nele são observadas possibilidades para os veres geográficos. A conceituação de bombas de nuances, de Paul Kingsburry (2010), nos é dada assim:
A noção de Nietzsche de bombas de nuances fornece uma maneira de manter em jogo apenas enigmas de arte traduzível, assim como a alteridade que reside na estética da vida cotidiana (...) Considerando as implicações da bomba Nietzschiana, podemos compreender o alcance do mundo efervescendo com lugares e coisas que são tão intensos como são sutis, tanto quanto são bonitos (Tradução do Grupo de Pesquisa Linguagens Geográficas). ${ }^{4}$

A Literatura é mais uma bomba de nuance, um lance de dados para contribuir com a construção de saberes na Geografia.

Buscamos relacionar nessa pesquisa a Geografia e a Literatura nas séries iniciais do ensino fundamental. Nesta modalidade de ensino, a Geografia é um componente curricular que figura ao lado do ensino de Ciências, História, Artes, Educação Física, Matemática e o Ensino da Língua Materna, como assim está previsto nos Parâmetros Curriculares Nacionais (1997). O ensino de todos os componentes curriculares é feito por um mesmo professor, o chamado professor polivalente, com formação em Magistério na Modalidade Normal ou nos cursos de Pedagogia, como previsto na Lei de Diretrizes e Bases da Educação Nacional (1996).

A pesquisa começou com a motivação exposta nas linhas anteriores: a de juntar olhares diversos sobre o mundo, a fim de que a Geografia pudesse ser prenhe de sentidos e significados para o aluno, desde o seu ingresso nas séries iniciais. Observamos também a menção que Douglas Santos (2010, p.193) faz do papel da literatura na escola e o lugar do professor em relação a este assunto:

A literatura traz as mazelas e as dores,
as alegrias e os prazeres humanos,
numa reflexão que te permite a paixão.
Beber num diálogo muito interessante,
com os chamados segmentos áridos, da
ciência e da filosofia etc., para que eles
tornem-se essa paixão. Então, uma
coisa sem a outra, não existe. Todos
devemos oferecer aos nossos jovens e
às nossas crianças, a possibilidade da
imaginação, a possibilidade de olhar o
mundo sob diferentes focos ou pers-
pectivas.

E ainda mais nos detivemos à questão do desenvolvimento infantil, atendo-nos à importância da imaginação para o desenvolvimento cogniti-

\footnotetext{
${ }^{4}$ Original em inglês: "Nietzsche's notion of explosive nuance provides one way in which to keep in play the barely translatable enigmas of art, as well as the otherness that resides in the aesthetics of the everyday (...) By considering the Nietzschean bomb of nuance, we can apprehend the extent to which the world fizzes with places and things that are as intense as they are subtle as they are beautiful.
} 
vo da criança. Esta que ingressa nas séries iniciais do Ensino Fundamental com 6 anos ${ }^{5}$, segundo as fases de desenvolvimento de Piaget, encontra-se no período operatório-concreto, cuja capacidade de abstração ainda é reduzida e irá ampliar-se no convívio com crianças maiores e com diversas situações desafiadoras.

A Literatura parece ser um meio de aproximar as vivências, as peculiaridades do universo aos significados e buscas que o ser humano em seu desenvolvimento intelectual, motor e psicológico apresenta; a literatura infantil, que contêm em si linguagem e enredo que dialogam com o espaço infantil, visa atender as particularidades dos anseios e necessidades dessa faixa etária. Segundo Bruno Bettelheim (2004, p. 3) em cada idade "buscamos e devemos ser capazes de achar alguma quantidade módica de significado congruente com o 'quanto' nossa mente e compreensão já se desenvolveram".

Esta "quantidade módica de significado" está intrinsecamente ligada às necessidades cognitivas da criança para que ela se referencie no mundo, entendendo as relações de vizinhança, de semelhança, de diferença, e passe a ver o outro enquanto partícipe de uma mesma realidade, mas com uma vida diversa da sua.

A construção da noção escalar, e da compreensão das relações de vizinhança é tema extremamente geográfico e deve ser explorado nas séries iniciais do Ensino Fundamental. O professor, que passa boa parte do tempo atentando para o ensino da Língua Materna pode perfeitamente fazê-lo, mas sem descuidar dos conteúdos que podem auxiliar o aluno no processo de compreensão do espaço vivido, em seu senso de localização.

A concepção de ciência que inter-relaciona a Geografia e a Literatura não pode estar atrelada ao entendimento usual de só existir uma maneira de se fazer conhecimento científico, ou seja, o modelo ou paradigma tradicional de se praticar ciência a partir de um método que visa atingir a verdade essencial, imutável e generalizante. Essa concepção de modelo científico, que toma os referenciais elaborados pelas ciências físicas e matemáticas como os mais capazes para se atingir a verdade inquestionável dos fatos, acaba por uniformizar e padronizar idealmente o mundo vivido em prol de modelos que facilitem a manipulação e o controle do mesmo, eliminando desse saber tudo aquilo que não se encaixa nesses parâmetros (FERRAZ, 2002).

0 trabalho com textos literários permite exatamente esse focar sobre os fenômenos e valo- res, comportamentos e ideias que escapam, como linhas de fuga, desse conhecimento disciplinador, ordenador e organicamente generalizador. Quando nas séries iniciais da vida escolar, o professor polivalente tem que trabalhar literatura, ele tende a não perceber esse texto como um conjunto de elementos que podem derivar para o sentido geográfico pertinente à faixa etária de seus alunos. Ele acaba nem vislumbrando que se poderia fazer até uma transposição didática, sem que esta seja feita de maneira forçosa, com um didatismo excessivo que tire o brilho e o apelo do texto literário.

Para a grande maioria dos professores, agora não só os das séries iniciais, o uso da literatura nas aulas de Geografia é para exemplificar determinado fenômeno ou conteúdo geográfico, como pegar um conto de algum escritor regionalista para enriquecer a imagem de determinada região ou fenômeno presente no livro didático. 0 contrário, ou seja, nas aulas de língua materna ou de literatura, quando a Geografia adentra, se adentra, é como uma espécie de mapa do lugar em que determinada trama ocorre, ou que o autor da mesma percorreu e reproduz essa em sua narrativa literária. Acaba, diante dessa situação, que não ocorre o diálogo necessário entre os saberes, tão somente um monólogo, em que um saber usa do outro de forma empobrecida.

Diante disso, torna-se necessária fundar um diálogo entre essas linguagens, mas tal ato significa colocar para conversar as imagens passíveis de serem criadas a partir do contato com a narrativa literária com as imagens presentes nas falas e silêncios presentes no espaço de vida dos alunos. Júlio Suzuki (2006, p.66), argui sobre as peculiaridades do espaço da narrativa e as preocupações do geógrafo:

Assim, o espaço da narrativa não é o mesmo com o qual trabalha o geógrafo, de maneira geral; tal pesquisador está preocupado com o movimento do mundo em que vivemos. Por mais que o mundo possa ser interpretado, e compreendido, de modos diferentes, não é o espaço da ficção. De qualquer maneira, o diálogo entre a Geografia e a Literatura constitui uma ponte que pode enriquecer tanto as análises realizadas lá como cá.

Lá como cá, eis os advérbios que reforçam aquilo que estamos a dizer sobre a relação entre a Geografia e a Literatura. Lá é o texto literário, aquilo

${ }^{5}$ A partir da Lei 11.274/2009, as crianças passaram a ingressar nas séries iniciais aos seis anos de idade, portanto um ano antes do que previa a legislação anterior. Disto resulta a criação de um ensino fundamental de 9 anos. 
que um autor escreveu, ficção ou não. 0 cá é onde está o aluno, do lado de cá do texto. Por ora, o lá e o cá se encontram e dialogam com o aluno, mostrando novos horizontes e possibilitando a construção de sentidos geográficos. É como na história Alice no País das Maravilhas, de Lewis Carrol. Quando cai no buraco, atraída pelo coelho de relógio e colete, Alice não imagina o que está por vir, e disto desencadeia novos referenciais de mundo para ela. 0 universo do coelho era para Alice um universo inexistente, até que ela não resiste à tentação e submerge para a toca. Ao que caindo ela reflete e fala sozinha (CARROL, 2002, p.7):

Deixe-me ver, até aqui eu já desci umas 400 milhas eu acho... (você vê Alice aprendeu uma porção de coisas desse tipo na escola e pensou que seria muito boa a oportunidade de colocar para fora seu conhecimento; mesmo não havendo ninguém para ouvi-la, ainda assim era bom praticar) (...) "Sim acho que está correto, mas em que Latitude e Longitude estaríamos?" Alice não tinha a mais leve ideia do que Latitude era, ou Longitude tampouco, mas ela pensava que eram boas palavras para dizer.

Alice está vivendo um dilema entre o que ela aprendeu na escola e aquilo que está vivenciando. $O$ que ela aprendeu serviria para algo? Se ela havia aprendido os nomes Latitude e Longitude, na certa estava ali uma boa oportunidade para usálos. No entanto, não havia ninguém para ouvir, nem tampouco mudou o fato de que ela invariavelmente cairia no buraco.

Não estamos dizendo que não é importante aprender as denominações, os conceitos e nomes dados aos fatos e objetos geográficos. $\mathrm{F}$ a $\mathrm{l}$ a $\mathrm{m} \mathrm{o} \mathrm{s}$ neste momento da promoção de sentidos e significados. Ao ler Alice para seus alunos, o professor não precisa chegar no aluno e lhe dissecar o conceito de latitude e longitude presente no texto. A ideia proposta é de, ao ler e debater o texto, o professor possa falar acerca dos referenciais novos de localização que Alice precisa criar para saber se orientar na nova terra. Ela parte dos referenciais que apreendeu, mas ali ficam desterritorializados, e assim reterritorializa outros a partir das condições percebidas e experimentadas.

Em que medida os alunos não estão também desterritorializando constantemente aquilo que estudaram em Geografia por não conseguirem aplica-los em muitas das situações de vida, precisando territorializar outros a partir do que já sabem, do que desconhecem, do que vislumbram como forma de sobrevivência no lugar em que se encontram? Esse é o questionamento que deve parametrizar o trabalhar com Geografia em sala de aula, independente do ciclo escolar em que os alunos e os professores se encontram.

Dialogar com os próprios referenciais de espaço que as crianças estão construindo em suas vidas, levar a cabo a ideia de que importa a forma pela qual pensamos o espaço", nos dizeres de Doreen Massey (2007), nos possibilita vislumbrar que não existe uma única forma de se olhar a espacialidade do mundo, muito menos só um modelo de se elaborar o conhecimento geográfico e, mais importante, por incrível que pareça, a Geografia é um conhecimento necessário não só para os interesses administrativos do Estado-Nação ou das grandes corporações econômicas, mas é imprescindível para os indivíduos melhor se orientarem e se localizarem no cotidiano de suas existências. Tomar a essa necessidade como um processo de alfabetização no sentido mais pleno do termo, move, ou deveria mover, a presença desse saber no currículo das séries iniciais, não somente como mais um componente curricular da grade escolar a ser cumprido.

Em que medida a Geografia pode ser acessível à criança nesta etapa de ensino? Para Rafael Straforini (2004, p.81), o ponto de partida é uma questão chave. 0 autor menciona que raramente $o$ professor inicia a aula lendo um jornal ou uma revista. Geralmente a aula se inicia com leitura do livro didático. E prossegue afirmando que:

Para a Geografia a ser estudada não
deve ser aquela enumerativa, descriti-
va, enciclopédica. Ela deve trabalhar
com a realidade do aluno, uma realida-
de de múltiplas relações. Ou como
propõe Demo (1998) todas as dimen-
sões que compõem a forma de viver e o
espaço que a cerca. O aluno deve ser
inserido dentro daquilo que está estu-
dando, proporcionado a compreensão
de que ele é um participante ativo na
produção do espaço geográfico.

Compartilhamos a ideia de que a Geografia a ser estudada deve compreender múltiplas relações, mas também múltiplas linguagens, principalmente aquelas que têm um apelo mais chamativo à faixa etária. A pintura, a música, a literatura compõem este rol de interesses, muito também devido à característica das crianças da faixa etária, onde a ludicidade e o contato com linguagens mais acessíveis ao seu pensar são fundamentais. Nesta fase a manipulação de objetos e a interação com o real são 
as bases para a cognição e constituem pontos de partida para a compreensão do mundo. Contudo, para melhor exemplificarmos essas questões, passemos para um estudo de caso.

\section{Para um final provisório: Geografia e Literatura em Dourados - MS}

Se, em vez disso, concebêssemos um encontro de histórias, o que aconteceria às nossas imaginações implícitas de tempo e espaço?

Doreen Massey (2007)

0 que trazemos à baila neste texto faz parte do trabalho que está sendo realizado no município de Dourados, o qual se situa na porção sudoeste do Mato Grosso do Sul. Dourados é uma cidade com 196.035 habitantes (IBGE, 2010), possui 32637 alunos matriculados no Ensino Fundamental, sendo que destes 28934 estavam matriculados em escolas públicas estaduais e municipais e 3703 estavam nas escolas particulares, segundo dados de 2009, também coletados pelo IBGE.

A condição de Dourados no cenário sulmato-grossense é de ser a cidade média mais próxima da fronteira com o Paraguai. Como a definição da área de fronteira no Brasil abrange 150 quilômetros de forma paralela à linha divisória ${ }^{6}$ entre os países, o município de Dourados se encontra no interior dessa faixa fronteiriça, portanto, possui características próprias quanto à legislação, além daquelas demandas e questões presentes em áreas de fronteira.

Ao iniciarmos a pesquisa de campo, em meados do ano de 2011, os professores das séries iniciais das escolas participantes da pesquisa demonstraram certa preocupação em expor seus métodos de trabalho e formas de conduzir suas aulas de Geografias. De antemão, a maioria já antecipou que seguia aquilo que estava no livro didático e os textos que lá estavam presentes.

Fomos aos livros didáticos. Neles pudemos perceber algo que nos surpreendeu: a Literatura Infantil estava bastante representada, através de textos que vão de Clarice Lispector a Tatiana Belinky, passando por Ruth Rocha, José Paulo Paes, Monteiro Lobato e tantos outros. Letras de música também são frequentemente utilizadas como recurso literário dentro dos livros didáticos analisados.

Ao todo foram pesquisados 35 professores de 7 escolas, assim como 35 livros didáticos (vide bibliografia). De maneira geral, os professores das séries iniciais tendem a abordar o conteúdo geográfico em separado dos demais conteúdos de outras disciplinas. As noções de geografia se restringem ao que os livros didáticos ou as orientações pedagógicas apontam, ou seja, são noções que os próprios professores desconhecem como escala, território, lugar, região etc.

Contudo, por ser uma região fronteiriça, como já apontado, assim como por possuir um grande contingente de população indígena, além de paraguaios, bolivianos, fora os muçulmanos, libaneses em sua maioria, gaúchos, nordestinos, além dos pantaneiros, quilombolas etc., a região e a cidade de Dourados é um mosaico de tradições culturais e de tensões ideológicas, políticas e econômicas. Ainda assim, a geografia trabalhada tende a superficializar, uniformizar e generalizar os conteúdos, restringindo-os ao que os livros didáticos, geralmente elaborados em São Paulo e Rio de Janeiro, trazem de informações. Resultado: as aulas de geografia acabam por não falar do lugar geograficamente em que os alunos se encontram. Ao mesmo tempo, os textos de literatura se restringem a abordar o conteúdo da gramática e domínio da escrita da língua, mas não agenciam outros encontros, principalmente com os de ordem espacial.

Dentre os textos literários foi possível observar que há muito material para que o professor possa tratar de questões geográficas de maneira a dialogar com a realidade da criança que cursa as séries iniciais do Ensino Fundamental. No município de Dourados, é ainda mais interessante ao professor abordar os textos literários com os quais possam tratar da questão da fronteira, das temáticas relacionadas à migração, à convivência com os indígenas, enfim, abordar temas que se encontram no lugar em a vida se espacializa, aproveitando os saberes do aluno, aquilo que ele refletiu sobre a história, relacionando-os aos conceitos geográficos.

Além disso, o exercício da imaginação que a leitura proporciona, leva também o aluno a entender a questão escalar, os conceitos de espaço e lugar, conceitos caros à Geografia.

Por ora estamos nos colocando a analisar os textos literários, pensando que há uma Geografia que não é matematizável, que não está preocupada com uma única corrente metodológica para entender o mundo. Enquanto fazemos a análise dos textos literários estamos também nos propondo a pensar que, na História de Peter Pan, por exemplo, existe uma questão territorial fundamental para o leitor, ponto de partida para iniciar a aprendizagem e discussão deste conceito. Que há no conhecido texto dos Três Porquinhos uma discussão que remete à discutir o lugar, o pertencimento, os hábitos de

${ }^{6}$ Lei no 6.634, de 2 de maio de 1979: Dispõe sobre a Faixa de Fronteira, altera o Decreto-lei no 1.135, de 3 de dezembro de 1970, e dá outras providências. 
vida, enfim. Um texto literário não é somente um amontoado de palavras a partir o momento em que é lido, imaginado e refletido. A Geografia não é apenas uma compilação de experiências cientificas e teorias a partir do momento em que é colocada em movimento e confrontada com o espaço vivido. A partir daí ela passa a ser produzida, a conversar com os interessados em compreendê-la.

Para trabalhar com o tema Eu e outras crianças, o livro didático da coleção Asas para Voar, do segundo ano, lança mão de um fragmento do livro $A$ vida íntima de Laura, de Clarice Lispector. Após o pequeno trecho faz algumas perguntas sobre o texto. Mas vamos ao fragmento que está no livro:

Laura vive apressadinha.

Por que tanta pressa, oh, Laura?

Pois ela não tem nada o que fazer.

Esta pressa é uma das bobagens de Laura.

Mas ela é modesta:

basta lhe cacarejar um bate-papo

sem-fim com as outras galinhas.

As outras são muito parecidas com ela: também meio ruiva e meio marrom.

Só uma galinha é diferente delas:

Uma carijó toda de enfeites

preto-e-branco.

Mas elas não desprezam a carijó por ser de outra raça. (...)

O livro didático busca reforçar a importância da diversidade, e depois o texto faz questões sobre a diferença entre a galinha Laura e a galinha carijó. Busca fazer o aluno levar em conta que a aparência não importa, que ser de uma outra raça não faz com que galinha menospreze a companheira. Mas, sem desprezar a forma como o livro se utilizou do texto vamos voltar um pouco à vida intima de Laura, a fim de vermos quantas outras geografias estão presentes neste texto (desta vez em todo o livro). Vamos explorar ainda algo que há de muito interessante sobre a autora, conhecida por seu intimismo: Clarice Lispector fala de "dentro para fora". Seus personagens são carregados de uma subjetividade que remete à subjetividade a ser salva" que Theodor Adorno preconizava. Quanto a esta subjetividade a ser salva, Slavoj Zizek, 1992, p.46, reflete que:

A filosofia, que habita na coerção da linguagem, recalca essa descentração interna, essa dependência da rede lingüística que concerne a seu próprio interior, e faz da linguagem um instrumento externo, objeto da retórica: "A retórica representa, na filosofia, o que não pode ser pensado de outra maneira senão na linguagem" (ibid). Reconhecer essa "primazia do objeto" é, segundo Adorno, a única maneira de salvar a subjetividade"(...).

A narradora nos conta que Laura era uma galinha "bastante burra. Tem gente que acha ela burríssima, mas isto também é exagero: quem conhece bem Laura é que sabe que Laura tem seus pensamentozinhos e sentimentozinhos.", (2010, p. 6). Apesar de burra, Laura era uma excelente botadeira. Botava mais ovos que todas as outras, era muito limpa, mas também muito medrosa. E assim começa a caracterização da personagem principal.

Clarice deixa-nos perceber durante toda a história que, a burrice de Laura não a torna incapacitada para a sua função haja vista que "ela é a galinha que bota mais ovos em todo o galinheiro e mesmo nos das vizinhanças", (2010, p. 7). No entanto, persiste um grande medo do mundo e das pessoas. Este receio de tudo que a rodeia, talvez advenha de sua incompreensão acerca dele. A não compreensão do espaço e das nuances que saem dele muitas vezes são propulsoras de uma busca por linhas de fuga, no sentido deleuzoguattariano, ou de uma anulação total do ser de tal forma que, ou há uma ruptura ou ele explode.

É então que, ao ficar mais velha, menos produtiva, porém ainda em condições de virar comida, Laura vai ter o destino de todas as outras galinhas da casa, virar um molho pardo. Ela aceita seu desígnio, pois acredita que "é muito melhor morrer sendo útil e gostosa para uma gente que sempre me tratou bem, essa gente, por exemplo, não me matou nenhuma vez." ${ }^{7}$ (2010, p. 13). No entanto, ao se ver ameaçada verdadeiramente por seu destino inevitável ela consegue simular que é uma outra galinha e passa despercebida pela cozinheira. Sua sobrevivência foi assegurada pela capacidade de recriarse, de lançar novas Geografias acerca de si e do outro, de simular novos territórios e novas funções para si. Esta é só uma mostra de quantas geografias podem estar por trás de um texto, como o Lispector, que esbanja multiplicidades e sentidos.

0 fio condutor do trabalho que relaciona Literatura e Geografia depende muito do professor e da maneira como os questionamentos e debates acerca dos textos serão feitos. Este não é um trabalho mecânico, não possibilita a compilação de ensinamentos numa cartilha em que haja detalhadamente o como fazer. Exige um posicionamento de que a Geografia é importante nas séries iniciais e que deve estar em constante dialogo com outros saberes produzidos em diversasáreas do conhecimento.

${ }^{7} \mathrm{O}$ narrador complementa que a galinha é tão burra que acredita que se morre mais de uma vez. 


\section{Referências}

ALVES, Rubem. Entre a ciência e a sapiência- o dilema da educação. São Paulo: Editora Loyola, 1996

BORGES, Luís. Cuarto Congreso Mundial de Lectura. Buenos Aires, 1972.

BRASIL. MINISTÈRIO DA EDUCAÇÃO. SECRETARIA DE EDUCAÇÃO BÁSICA. Parâmetros Curriculares Nacionais de Geografia. Ministério da Educação. Secretaria de Educação Básica: Brasília (DF), 1997.

CHIANCA, R. B. \& TEIXEIRA, F.M.P. Coleção Pensar \& Viver: Geografia. São Paulo, Ática, 2001.

DELEUZE, Gilles \& GUATTARI, Felix. Mil Platôs: Capitalismo e Esquizofrenia. Vol 1. São Paulo: Editora 34, 1995.

FERRAZ, Cláudio Benito O. Para pensar a Geografia para além do bacharel e do licenciado. In: NUNES, Flaviana G. (org.). Caminhos da Geografia para o século XXI. Cascavel (Pr.): EDUNIOESTE, 2006, p. 13 - 43.

GOETTERT, Jones D.; MARSCHNER, Walter R. (orgs.). Transfazer o Espaço: ensaios de como a literatura vira espaço e vice-versa. Dourados (MS): Ed.UFGD, 2011.

HUMBOLDT, A.V. COSMOS: A Sketch of the Physical Description of the Universe, Vol. 1 Traduzido por: E. C. Otte.Volume1. Edição: Harper \& Brothers, 1958

KINGSBURY, P. Unearthing Nietzsche's Bomb: Nuance, Explosiveness, Aesthetics. In: ACME: An International EJournal for Critical Geographies, 2010, 9 (1), 48-61

MARANDOLA Jr., Eduardo; GRATÃO, Lúcia H. B. Geografia e Literatura: ensaios sobre geograficidade, poética e imaginação. Londrina (Pr.): EDUEL, 2010.
MASSEY, Doreen. Pelo espaço: por uma nova política da espacialidade. Rio de Janeiro, Bertrand Brasil, 2007.

MENEZES, Ebenezer T.; SANTOS, Thais H. Transposição didática (verbete). Dicionário Interativo da Educação Brasileira - EducaBrasil. São Paulo: Midiamix Editora, 2002, http://www.educabrasil.com.br/eb/dic/ dicionario.asp?id=23, acesso em 22/3/2012.

MONTEIRO, Carlos A. F. O Mapa e a Trama: ensaios sobre o conteúdo geográfico em criações romanescas. Florianópolis: Ed. Da UFSC, 2002.

MOREIRA, Ruy. Grande Sertão: Veredas, na trilha de uma geografia roseana. Revista Fluminense de Geografia. Niteroi: UFF, ano1, no 1, p. 41-49, 1996.

CORRÊA, Roberto L.; ROSENDAHL, Zeny (orgs.). Literatura, Música e Espaço. Rio de Janeiro: EDUERJ, 2007.

SANTOS, Douglas. Entrevista à revista Entre-Lugar. Entre Lugar. Dourados (MS): UFGD, ano 1, n. 2, p. 183193, 2ºmestre de 2010.

SANTOS, Douglas. o que é Geografia? (Material de apoio ao mini-curso ministrado

no VI Encontro Nacional de Ensino de Geografia "Fala Professor"). Uberlândia (MG): Associação dos Geógrafos Brasileiros, 2007.

SIMIELLI, M.H. Coleção Asas para Voar: $1^{\circ}$ ao $5^{\circ}$ ano. São Paulo: Editora Ática, 2010.

STRAFORINI, Rafael. A Totalidade Mundo Nas Primeiras Séries do Ensino Fundamental: um Desafio a ser enfrentado. Terra Livre São Paulo Ano 18 , vol. I, n. 18 p. 95 - 114 jan.-jul./ 2.002

ZIZEK, Slavoj. Eles não sabem o que fazem: o sublime objeto da ideologia. [tradução de Vera Ribeiro]. Rio de Janeiro: Jorge Zahar Editor, 1992. 


\title{
Music geography and space politics: Antonin Dvořák's Symphony n. 9 and the American Nationalism
}

\begin{abstract}
The present study explores the relation between geography and literature in the early grades of elementary school. Working with the early grades is a challenge, as it commonly graduated in Geography teachers working in upper grades of elementary school and high school. However, it is a matter that concerns the geography as a whole because the rooms of the initial series geographical science is being put into motion, and believe it has a key role in student education, both in their school life, as in their relationship in world around him. As we are talking about grades and a student body of 59 years or so, let us look over the relationship between geography and Children's Literature. The place of research, Dourados, municipality which is southwest of the state of Mato Grosso do Sul is located in the border area (Brazil-Paraguay), and makes it even more interesting work to relate the Geography with Children's Literature. This is because its location is relatively distant from major publishing centers, and it is apparent that the textbooks do not have much relation to reality of the place, the border issue and its specificities. The Children's Literature can be a shortcut to the teacher, a way of being close to the teaching of Mother Language (over charged as a curriculum component in institutional evaluations of the Evaluation System of Basic Education), while teaching in an interesting and evaluative Geography, brings clairvoyance to questions about the living space. During the occurrence of research, many interesting texts were found in the textbooks cited by Geography teachers from seven schools in the city of Dourados-MS. The analysis of these texts is possible to infer that, through the Children's Literature Geography is possible to speak of a perspective that recognizes the a priori knowledge of the student at the same time, expand your knowledge of the world and is a science endowed with meaning and significance in everyday life Student of the initial series.

Keywords:Geography. Children's Literature. Initials Series. Curriculum.
\end{abstract}

\section{Dialogue entre la et la litterature dans la petite enfance education élémentaire}

Résumé: La présente étude explore la relation entre la géographie et la littérature dans les premières années de l'école élémentaire. Travailler avec les premières années est un défi, car il est diplômé en commun des enseignants Géographie de travail dans les classes supérieures de l'école élémentaire et l'école secondaire. Cependant, il est une question qui concerne la géographie dans son ensemble parce que les chambres de la science première série géographique est mis en mouvement, et nous croyons qu'il a un rôle clé dans la formation des étudiants, à la fois dans leur vie scolaire, comme dans leur relation au monde autour de lui. Comme nous parlons grades et un corps étudiant de 5-9 ans environ, penchons-nous sur la relation entre la géographie et la littérature pour enfants. La place de la recherche, d'or, d'une municipalité qui est sud-ouest de l'État du Mato Grosso do Sul est situé dans la zone frontalière (Brésil-Paraguay), et rend le travail encore plus intéressant de relier la géographie avec la littérature pour enfants. C'est parce que son emplacement est relativement éloignées des centres principaux d'édition, et il est évident que les manuels n'ont pas grand rapport avec la réalité du lieu, la question des frontières et de ses spécificités. La littérature pour enfants peut être un raccourci pour l'enseignant, une façon d'être proche de l'enseignement de la langue maternelle (trop chargé en tant que composante du curriculum dans les évaluations institutionnelles du système d'évaluation de l'éducation de base), tout en enseignant dans une intéressante et évaluative Géographie, apporte clairvoyance à des questions sur l'espace de vie. Au cours de la recherche en cours de nombreux textes intéressants ont été trouvés dans les manuels cités par les enseignants Géographie de sept écoles de la ville de Dourados-MS. L'analyse de ces textes est possible d'en déduire que, à travers la géographie de littérature pour enfants est possible de parler d'une perspective qui reconnaît la connaissance a priori de l'étudiant dans le même temps, élargir vos connaissances du monde et est une science dotée de sens et de signification dans la vie quotidienne étudiants de la série initiale.

Mots-clés: Littérature Pour Enfants. Premières Années. Programme. 